\title{
Psychological adaptation to human sperm competition
}

\author{
Todd K. Shackelford ${ }^{\mathrm{a} *}$, Gregory J. LeBlanc ${ }^{\mathrm{a}}$, \\ Viviana A. Weekes-Shackelford ${ }^{\mathrm{a}}$, April L. Bleske-Rechek ${ }^{\mathrm{b}}$, \\ Harald A. Euler ${ }^{\mathrm{c}}$, Sabine Hoier ${ }^{\mathrm{c}}$ \\ a Division of Psychology, Florida Atlantic University, 2912 College Avenue, Davie, FL 33314, USA \\ ${ }^{\mathrm{b}}$ Vanderbilt University, Nashville, TN, USA \\ ${ }^{\mathrm{c}}$ University of Kassel, Kassel, Germany
}

Received 21 December 1999; received in revised form 23 February 2000; accepted 6 September 2001

\begin{abstract}
Sperm competition occurs when the sperm of two or more males simultaneously occupy the reproductive tract of a female and compete to fertilize an egg. We used a questionnaire to investigate psychological responses to the risk of sperm competition for 194 men in committed, sexual relationships in the United States and in Germany. As predicted, a man who spends a greater (relative to a man who spends a lesser) proportion of time apart from his partner since the couple's last copulation reported (a) that his partner is more attractive, (b) that other men find his partner more attractive, (c) greater interest in copulating with his partner, and (d) that his partner is more sexually interested in him. All effects were independent of total time since the couple's last copulation and the man's relationship satisfaction. Discussion addresses two failed predictions and directions for future work. (C) 2002 Elsevier Science Inc. All rights reserved.
\end{abstract}

Keywords: Sperm competition; Evolutionary psychology; Human sexuality

\section{Introduction}

Sperm competition occurs when the sperm of two or more males simultaneously occupy the reproductive tract of a female and compete to fertilize an egg (Baker \& Bellis, 1995;

* Corresponding author. Tel.: +1-954-236-1179; fax: +1-954-236-1099.

E-mail address: tshackel@fau.edu (T.K. Shackelford). 
Parker, 1970a, 1970b, 1984). Sperm Competition Theory provides the theoretical framework for a body of work investigating adaptations in males and in females designed to solve problems posed by sperm competition (Parker, 1970a, 1970b; Smith, 1984a). Current research on the evolutionary causes and consequences of sperm competition focuses primarily on birds (Birkhead \& Møller, 1992) and insects (Gage, 1995; Thornhill \& Alcock, 1983). The research on sperm competition in birds is particularly interesting for students of human mating.

Over $90 \%$ of bird species practice social monogamy, the mating system most common to humans (Birkhead \& Møller, 1992). Social monogamy is a mating system in which a male and a female form a long-term pair bond. Within this mating system, a male benefits by gaining sexual access to the reproductive value of a female, whereas a female benefits by gaining access to the paternal investment of the male in her offspring (Birkhead \& Møller, 1992; Trivers, 1972). Only rarely is this exchange of reproductive resources between a male and a female exclusive, however. Recent work, including DNA fingerprinting to identify paternity, documents that social monogamy in birds does not necessarily indicate sexual and genetic monogamy (e.g., Burke, Davies, Bruford, \& Hatchwell, 1989). Female infidelity in socially monogamous birds is widely documented and is the primary context for sperm competition (Birkhead \& Møller, 1992).

When a female bird in a socially monogamous mateship is sexually unfaithful to her partner, she places her partner at risk of investing his limited time and resources in offspring to whom he is genetically unrelated. Female infidelity places selective pressures on males to detect the infidelity and to inflict costs on an unfaithful female. These costs include abandoning, raping, and physically assaulting an unfaithful female (Birkhead \& Møller, 1992). The costs inflicted by a male bird on a partner suspected of infidelity reveal psychological features designed to motivate behaviors that might "correct" the infidelity by an immediate or forced copulation, for example. These actions might be corrective in the sense that the in-pair male is placing his sperm in the female's reproductive tract, providing his sperm an opportunity to compete with the sperm of a rival male for the fertilization of his partner's eggs.

The socially monogamous mating system of birds - and the female infidelity that is the primary context for sperm competition - is characteristic of several primates, including humans. Humans are socially monogamous, with both males and females engaging in extrapair mating under certain predictable conditions (Baker \& Bellis, 1995; Buss, 1994). Baker and Bellis (1995) and Smith (1984b) provided empirical and theoretical arguments that female infidelity is the primary context for sperm competition in humans. Work by evolutionary psychologists, in turn, has identified the conditions under which female infidelity occurs and, furthermore, the costs that a male inflicts on a female partner who is suspected of infidelity. Shackelford and Buss (Buss \& Shackelford, 1997a, 1997b, 1997c; Shackelford \& Buss, 1997a, 1997b, 2000), for example, documented that female infidelity is associated with her personality characteristics, her partner's personality characteristics, and the discrepancy in mate value between her and her partner. Shackelford and Buss also identified some of the costs that a male inflicts on a partner that he suspects of infidelity. These costs include physical and psychological abuse, rape, and divorce (Buss \& Shackelford, 1997a, 1997b; Shackelford \& Buss, 1997a, 1997b). 
Human sperm competition has become a recent focus of evolutionary biologists and evolutionary psychologists (Baker \& Bellis, 1988, 1989a, 1989b, 1993a, 1993b, 1995; Bellis \& Baker, 1990; Gangestad \& Thornhill, 1997, 1998; Pound, 1998; Singh, Meyer, Zambarano, \& Hulbert, 1998; Thornhill, Gangestad, \& Comer, 1995). Baker and Bellis (1993a, 1995), for example, documented that male humans, like male birds, male insects, and other male nonhuman primates, appear to be physiologically designed to solve the adaptive problems of sperm competition. Studying couples in committed, sexual relationships, Baker and Bellis assessed (decreased) risk of sperm competition as the proportion of time a couple has spent together since their last copulation, controlling for the total time since their last copulation. As hypothesized, and consistent with Sperm Competition Theory, Baker and Bellis documented a large positive correlation between the risk of sperm competition and the number of sperm a male inseminates into his partner at the couple's next copulation.

Baker and Bellis investigated physiological reactions to the risk of sperm competition. There must be psychological mechanisms linked to these physiological adjustments. Male psychology may include evolved mechanisms that motivate behavior that would have increased the probability of success in sperm competition for ancestral males. The present research seeks to identify some of these evolved mechanisms and their associated design features.

Baker and Bellis operationalized risk of sperm competition as the proportion of time a couple has spent together since their last copulation. As this proportion decreases, the risk that a rival male will inseminate a woman increases (Baker \& Bellis, 1995). The proportion of time that a couple has spent together since their last copulation is perfectly negatively correlated with the proportion of time that a couple has spent apart since their last copulation. The proportion of time spent apart since the couple's last copulation is arguably a more intuitive index of the risk of sperm competition, and we therefore refer to the proportion of time spent apart rather than the proportion of time spent together. We propose that the proportion of time that a couple has spent apart since their last copulation is information processed by male psychological mechanisms that subsequently motivates a man to want to inseminate his partner as soon as possible, to combat the increased risk of sperm competition.

Total time since last copulation is not clearly linked to the risk of sperm competition. Instead, it is the proportion of time a couple has spent apart since their last copulation - time during which a man cannot account for his partner's activities - that is linked to the risk of sperm competition (Baker \& Bellis, 1995). Nevertheless, it might be argued that total time since last copulation is the relevant variable. As the total time since last copulation increases, a man might feel increasingly "sexually frustrated" and, therefore, increasingly interested in copulation with his partner, independent of the proportion of time he and his partner have spent apart since their last copulation. We could not locate any research that investigated the relationship between a man's sexual interest in his partner and the total time since the couple's last copulation. To address the potential confound, however, we assessed the relationships between male sexual psychology and behaviors predicted to be linked to the risk of sperm competition (as assessed by the proportion of time spent apart since last copulation), independent of the total time since a couple's last copulation. 
A man's sexual interest in his partner, for example, might be higher with a greater proportion of time spent apart from his partner since their last copulation, but only for a man who is satisfied with his relationship. A man who is more satisfied with or invested in his relationship may have more to lose in the event of cuckoldry. More generally, a man's satisfaction with the relationship might be related to his reported sexual interest in and attraction to his partner. Unlike a greater proportion of time spent apart since the couple's last copulation, a man's satisfaction with the relationship is not clearly linked to the risk of sperm competition. To address this possible confound, however, we investigated the relationships between male sexual psychology and behaviors predicted to be linked to the risk of sperm competition (as assessed by the proportion of time spent apart since last copulation), independent of a man's relationship satisfaction.

In summary, this research tested the hypothesis that human male psychology includes evolved mechanisms designed to attend to the risk of sperm competition as assessed by the proportion of time a couple has spent apart since their last copulation, independent of (a) the total time since the couple's last copulation and (b) the man's relationship satisfaction. A key component of this hypothesis is that the output of these evolved mechanisms includes increased motivation to copulate with one's partner. We generated six predictions from this hypothesis. A man may be more likely to want to copulate with his partner when he perceives his partner as more attractive. This leads to the first prediction:

Prediction 1: A man who spends a greater (relative to a man who spends a lesser) proportion of time apart from his partner since the couple's last copulation will rate his partner as more attractive, independent of (a) the total time since last copulation and (b) relationship satisfaction.

A man who perceives that other men find his partner attractive might, as a consequence, perceive his partner as more attractive. This effect might occur because the perception that other men find his partner attractive is a cue to increased risk of sperm competition, should these other men pursue copulation with his partner. Or this effect might occur because the perception that other men find his partner attractive draws his attention to his partner's attractiveness. Following Prediction 1, the greater perceived attractiveness of his partner might motivate a desire to copulate with his partner as soon as possible.

Prediction 2: A man who spends a greater (relative to a man who spends a lesser) proportion of time apart from his partner since the couple's last copulation will provide higher ratings of other men's assessments of his partner's attractiveness, independent of (a) the total time since last copulation and (b) relationship satisfaction.

A man's self-reported desire to copulate with his partner presumably predicts his active pursuit of copulation with his partner. This assumption leads to the third prediction:

Prediction 3: A man who spends a greater (relative to a man who spends a lesser) proportion of time apart from his partner since the couple's last copulation will report greater interest in copulating with his partner, independent of (a) the total time since last copulation and (b) relationship satisfaction.

A man's perception that his partner is sexually interested in him may motivate him to pursue copulation with her. A man's perception that his partner is sexually interested in other men might also motivate him to pursue copulation with her. The perception that his partner is sexually attracted to other men may signal an increased risk of sperm competition or may highlight his partner's sexual needs, desires, and attractiveness. This focused attention on his 
partner's sexuality might motivate him to pursue copulation with her. Regardless of the proximate causal processes, we state the fourth and fifth predictions as follows:

Prediction 4: A man who spends a greater (relative to a man who spends a lesser) proportion of time apart from his partner since the couple's last copulation will provide higher ratings of his partner's sexual attraction to him, independent of (a) the total time since last copulation and (b) relationship satisfaction.

Prediction 5: A man who spends a greater (relative to a man who spends a lesser) proportion of time apart from his partner since the couple's last copulation will provide higher ratings of his partner's sexual attraction to other men, independent of (a) the total time since last copulation and (b) relationship satisfaction.

According to Strategic Interference Theory (Buss, 1989), negative emotions such as anger, frustration, and upset signal interference with a plan of action that was reproductively successful for our ancestors. These negative emotions call attention to the strategic interference and motivate removal of the source of interference. The intensity of the negative emotions corresponds to the intensity or severity of strategic interference. A woman's denial of her partner's request for copulation is predicted to cause feelings of distress in her partner. These feelings of distress might, first, call her partner's attention to the strategic interference and, second, motivate him to remove the source of interference - in this case, to negotiate when the next copulation will occur. A woman's denial of her partner's request for copulation is expected to generate a level of distress in her partner that corresponds to the current risk of sperm competition he faces and which is indexed by the proportion of time the couple has spent apart since their last copulation. This leads to Prediction 6:

Prediction 6: A man who spends a greater (relative to a man who spends a lesser) proportion of time apart from his partner since the couple's last copulation will report greater distress following his partner's denial of a request for copulation, independent of (a) the total time since last copulation and (b) relationship satisfaction.

To summarize, we predict that a man who spends a greater proportion of time apart from his partner since the couple's last copulation will rate his partner as more attractive, will provide higher ratings of other men's assessments of his partner's attractiveness, will report greater interest in copulating with his partner, will provide higher ratings of his partner's sexual attraction to himself and to other men, and will report greater distress following his partner's denial of a request for copulation. These findings are predicted to be independent of the total time since the couple's last copulation and independent of the man's relationship satisfaction. To test these predictions, we collected self-report data in the United States and in Germany from men in committed, sexual relationships.

\section{Methods}

\subsection{Participants}

Participants were 194 men currently in a committed, sexual, heterosexual relationship. Participants were drawn from universities and surrounding communities in two Western 
countries, the United States $(n=126)$ and Germany $(n=68)$. Across samples, the mean age of participants was 26.3 years, and the mean age of participants' partners was 25.2 years. The mean length of participants' relationships, across samples, was 55.9 months. The predictions assume that participants are involved in a committed relationship. We included in analyses data provided by men who were currently in a relationship that had lasted at least 1 year. Although this particular minimum criterion is somewhat arbitrary, it ensures that all participants were involved in a "committed" relationship in the sense that the relationship has lasted at least 1 year. Additional descriptive statistics are provided in Table 1.

\subsection{Materials}

Each participant completed a three-page survey titled "Short Survey About Men's Sexual Behavior." Each participant was instructed to answer the questions honestly and was

Table 1

Descriptive statistics for target variables

\begin{tabular}{|c|c|c|c|c|c|c|c|}
\hline \multirow[b]{3}{*}{ Variable } & \multicolumn{6}{|c|}{ Sample } & \multirow[b]{3}{*}{$t$} \\
\hline & \multicolumn{2}{|c|}{ Overall } & \multicolumn{2}{|c|}{ United States } & \multicolumn{2}{|c|}{ Germany } & \\
\hline & Mean & S.D. & Mean & S.D. & Mean & S.D. & \\
\hline Relationship duration (months) & 55.9 & 72.6 & 50.6 & 72.7 & 65.7 & 71.9 & -1.38 \\
\hline Own age (years) & 26.3 & 10.1 & 24.6 & 8.8 & 29.4 & 11.4 & $-3.23 * *$ \\
\hline Partner's age (years) & 25.2 & 9.4 & 23.6 & 8.3 & 28.2 & 10.6 & $-3.32 * *$ \\
\hline Total time since last copulation (hours) & 120.6 & 160.3 & 137.2 & 182.3 & 89.1 & 101.4 & 1.94 \\
\hline Proportion of time apart since last copulation & 0.6 & 0.3 & 0.6 & 0.3 & 0.6 & 0.3 & 0.78 \\
\hline Relationship satisfaction ${ }^{\mathrm{a}}$ & 7.4 & 1.3 & 7.5 & 1.3 & 7.1 & 1.3 & $2.30^{*}$ \\
\hline Own assessment of partner's attractiveness ${ }^{b}$ & 7.2 & 1.5 & 7.4 & 1.5 & 6.9 & 1.5 & 1.93 \\
\hline $\begin{array}{l}\text { Own rating of other men's assessments of } \\
\text { partner's attractiveness }{ }^{b}\end{array}$ & 6.8 & 1.6 & 7.2 & 1.4 & 6.2 & 1.7 & $4.48^{* * *}$ \\
\hline Disinterest in copulating with partner ${ }^{\mathrm{c}}$ & 1.5 & 0.9 & 1.3 & 0.9 & 1.7 & 0.9 & $-2.70 * *$ \\
\hline $\begin{array}{l}\text { Estimate of how sexually attracted } \\
\text { partner is to participant }{ }^{\mathrm{d}}\end{array}$ & 7.0 & 1.6 & 7.4 & 1.5 & 6.4 & 1.6 & $4.00 * * *$ \\
\hline $\begin{array}{l}\text { Estimate of how sexually attracted } \\
\text { partner is to other men }\end{array}$ & 4.0 & 2.4 & 4.2 & 2.4 & 3.6 & 2.3 & 1.59 \\
\hline $\begin{array}{l}\text { Hypothetical distress following partner's } \\
\text { denial of request for copulation }\end{array}$ & 3.6 & 2.2 & 3.7 & 2.4 & 3.4 & 1.9 & 0.99 \\
\hline
\end{tabular}

For the combined (United States and Germany) sample, $N=194$; for the United States sample, $n=126$; for the Germany sample, $n=68$. The $t$ values were generated by independent means tests of the differences between the United States and Germany.

${ }^{\text {a }}$ Composite variable (see text), with scale anchored by $0=$ not at all satisfied, $9=$ extremely satisfied.

${ }^{\mathrm{b}}$ Composite variable (see text), with scale anchored by $0=$ not at all attractive, $9=$ extremely attractive.

${ }^{\mathrm{c}}$ Composite variable constructed using log-transformed variables (see text).

${ }^{\mathrm{d}}$ Scale anchored by $0=$ not at all sexually attracted, $9=$ extremely sexually attracted.

${ }^{\mathrm{e}}$ Composite variable (see text), with scale anchored by $0=$ not at all distressed, $9=$ extremely distressed .

$* P<.05$ (two tailed).

$* * P<.01$ (two tailed).

$* * * P<.001$ (two tailed). 
reminded that his responses were anonymous. The first section of the survey collected demographic information, including the participant's age, his partner's age, and the length of their relationship. The second section of the survey addressed the key sexuality variables. First, each participant was asked how many hours had passed since he last had sexual intercourse with his partner. Next, each participant was asked how many hours he had spent together with his partner, including sleeping time, since he last had sexual intercourse with his partner. The next set of questions asked each participant to think about his feelings "at this moment in time" and to rate the following items, from $0=$ not at all to $9=$ extremely: How attractive does the participant think his partner is? How attractive do other men think the participant's partner is? How interested is the participant in having sex with his partner? How sexually attracted to the participant is the participant's partner? How sexually attracted to other men is the participant's partner? Finally, each participant was asked to indicate, in hours, when he would next like to have sexual intercourse with his partner.

The third section of the survey asked each participant to answer questions about how he would feel "at that moment in time" if his partner denied a request to have sexual intercourse with him. Each participant was asked to rate his resulting anger, frustration, and upset on a scale anchored by $0=$ not at all and $9=$ extremely. The fourth section of the survey asked each participant to rate his commitment to his partner and his overall, sexual, and emotional satisfaction with his partner. These ratings were made on a 10-point scale anchored by $0=n o t$ at all and $9=$ extremely.

The translation of the survey from English to German proceeded as follows: A bilingual speaker translated the English language survey into German. A second bilingual speaker unaware of the contents of the original English language survey back-translated the German language survey into English. The two bilingual speakers consensually resolved the few resulting discrepancies between the original English language survey and the back-translated English language survey.

\subsection{Procedures}

Data were collected from two sources. First, students in social science courses were asked to voluntarily complete the survey during the last few minutes of a class session. Second, trained research assistants approached prospective participants at various locations on and around university campuses. These locations included coffee shops, shopping malls, and airports. The research assistant approached a man and asked if he would be interested in completing a short survey about sexuality. If the prospective participant was interested, the research assistant then asked if he was currently in a committed, sexual, heterosexual relationship. If these criteria were met, the research assistant handed the participant a consent form, the survey, and a $9 \times 12$-in. brown security envelope. The participant was instructed to read and sign the consent form, complete the survey, place the completed survey in the envelope, and then seal the envelope. The participant was instructed not to seal the consent form inside the envelope to maintain anonymity. Finally, the participant was instructed to place the sealed envelope in a box that contained other sealed envelopes. The participant was asked to place the signed consent form in a separate envelope that contained other signed 
consent forms. The research assistant explained to the participant the purpose of the study, answered any questions, and thanked the participant for his participation.

The procedure for data collection in class settings began with a trained research assistant explaining that men were needed for a study on sexuality in committed, sexual, heterosexual relationships. This request for participants occurred during the last few minutes of a class session. The research assistant explained that men in a committed, sexual relationship that were interested in voluntarily completing a short survey on sexuality in their relationship should remain in the classroom. Students who did not fit the criteria or who did not want to participate were given several minutes to exit the classroom. The remainder of the procedure for classroom data collection was identical to the procedure described above for the public approach method. About half the participants in the United States and in Germany were obtained through the public approach method. Most participants completed the survey in 3-5 $\mathrm{min}$.

\section{Results}

We used multiple regression analyses to test the six predictions. An important assumption of multiple regression and other parametric statistical analyses is that the independent variables are approximately normally distributed (see Tabachnick \& Fidell, 2001). Nonnormal distribution or skewness can be corrected in several ways, the most common of which is logarithmic transformation of the skewed variable (Tabachnick \& Fidell, 2001). Three variables were log transformed prior to analyses to correct substantial skew: (a) total time since the couple's last copulation, (b) desired time to next copulation with partner, and (c) interest in sex with partner. The proportion of time the couple had spent apart since their last copulation was calculated by subtracting the number of hours the couple had spent together since their last copulation from the total number of hours since the couple's last copulation and dividing this difference by the total number of hours since the couple's last copulation.

Several variables examined were composites. Relationship satisfaction $(\alpha=.78)$ is the mean of four variables: (a) participant's overall satisfaction, (b) sexual satisfaction, (c) emotional satisfaction with his partner, and (d) participant's commitment to his partner. Own rating of partner's attractiveness $(\alpha=.86)$ is the mean of two variables: Own rating of partner's (a) sexual attractiveness and (b) physical attractiveness. Own rating of other's assessment of partner's attractiveness $(\alpha=.88)$ is the mean of two variables: Own rating of other's assessment of partner's (a) sexual attractiveness and (b) physical attractiveness. Disinterest in copulating with partner $(\alpha=.65)$ is the mean of two log-transformed variables: (a) desired time to next copulation with partner and (b) interest in sex with partner (reverse coded). Finally, hypothetical distress following partner's denial of a request for copulation $(\alpha=.87)$ is the mean of three variables: (a) anger, (b) frustration, and (c) upset following partner's denial of a request for copulation.

Table 1 presents descriptive statistics for the key variables, across both samples and separately for the American and German samples. Table 1 also displays the results of independent means tests of country-of-origin differences on these variables. The German men 
and their partners were older than the American men and their partners. Relative to the German men, the American men reported greater relationship satisfaction, provided higher ratings of other men's assessments of their partners' attractiveness, reported greater interest in copulating with their partners, and provided higher ratings of their partners' sexual attraction to them (the participants). The German and American participants did not differ significantly in relationship duration, the total time since last copulation with their partners, the proportion of time spent apart from their partners since last copulation, assessments of partners' attractiveness, ratings of partners' sexual attraction to other men, or distress following their partners' denial of a request for copulation.

To increase the power of the statistical analyses, we collapsed the data across country. These results are presented in Table 2 and discussed below. In addition, we analyzed the data separately by country. The pattern of results when analyzed separately by country was the same as when analyzed across countries. For one of the country-level analyses (testing Prediction 4, regarding partner's sexual attraction to the participant), the significant effects found in the across-country analyses held for the American sample but not the German sample. For the remaining country-level analyses, significant effects identified in the acrosscountry analyses were in the same direction but did not reach statistical significance. For reportorial efficiency and to capitalize on greater statistical power, we present only the results

Table 2

Results of multiple regressions of proportion of time spent apart since last copulation, total time since last copulation, and relationship satisfaction on target dependent variables

\begin{tabular}{|c|c|c|c|c|c|c|}
\hline \multirow[b]{3}{*}{ Dependent variable } & \multicolumn{6}{|c|}{ Predictor variable } \\
\hline & \multicolumn{2}{|c|}{$\begin{array}{l}\text { Proportion of } \\
\text { time spent apart } \\
\text { since last copulation }\end{array}$} & \multicolumn{2}{|c|}{$\begin{array}{l}\text { Total time } \\
\text { since last copulation } \\
\text { (log transformed) }\end{array}$} & \multicolumn{2}{|c|}{$\begin{array}{l}\text { Relationship } \\
\text { satisfaction }\end{array}$} \\
\hline & $B$ & $t$ & $B^{\mathrm{a}}$ & $t$ & $B$ & $t$ \\
\hline $\begin{array}{l}\text { Own assessment of partner's attractiveness } \\
\text { (Prediction 1) }\end{array}$ & 0.70 & $2.01 *$ & 0.92 & 1.02 & 0.66 & $8.68 * * *$ \\
\hline $\begin{array}{l}\text { Own rating of other men's assessments of } \\
\text { partner's attractiveness (Prediction 2) }\end{array}$ & 0.95 & $2.34 *$ & 0.38 & 0.36 & 0.52 & $5.78 * * *$ \\
\hline $\begin{array}{l}\text { Disinterest in copulating with partner } \\
\text { (Prediction 3) }\end{array}$ & -0.56 & $-2.24^{*}$ & 0.60 & 0.92 & -0.16 & $-2.93 * *$ \\
\hline $\begin{array}{l}\text { Estimate of how sexually attracted partner } \\
\text { is to participant (Prediction 4) }\end{array}$ & 1.23 & $2.95 * *$ & -0.90 & -0.82 & 0.42 & $2.95 * *$ \\
\hline $\begin{array}{l}\text { Estimate of how sexually attracted } \\
\text { partner is to other men (Prediction 5) }\end{array}$ & -0.01 & -0.02 & 2.40 & 1.36 & -0.02 & -0.02 \\
\hline $\begin{array}{l}\text { Hypothetical distress following partner's } \\
\text { denial of request for copulation (Prediction 6) }\end{array}$ & 0.43 & 0.69 & -0.82 & -0.51 & -0.48 & $-3.49 * *$ \\
\hline
\end{tabular}

$N=194$ men. $B=$ unstandardized regression coefficient, $t=$ test statistic associated with $B$.

" For reportorial efficiency, the $B$ value shown for "Total time since last copulation" was produced by multiplying the original $B$ value by 10 .

$* P<.05$ (two tailed).

$* * P<.01$ (two tailed).

$* * * P<.001$ (two tailed). 
of analyses conducted on data collapsed across country (country-level analyses are available from the first author upon request).

We tested each of the six predictions with multiple regression. For each prediction, three predictors were entered into a regression equation predicting a single dependent variable. These three predictors were (a) the proportion of time the couple spent apart since their last copulation, (b) the total time since the couple's last copulation (log transformed), and (c) the participant's relationship satisfaction. Each prediction states that the proportion of time spent apart since the couple's last copulation will predict the target dependent variable, independent of the total time since the couple's last copulation and independent of the participant's relationship satisfaction. One of the reviewers of this article inquired as to whether we could analyze the results as a function of method of data collection (classroom versus public approach). Unfortunately, we did not code the surveys for method of data collection (although we estimate that about half the data were collected by each method), and so we cannot conduct these analyses.

Table 2 presents the results of the six multiple regressions conducted to test the six predictions. Table 2 presents, for each multiple regression, the standardized regression coefficient and the associated $t$ value for each of the three predictors. The first row of Table 2 shows that the greater the proportion of time a couple has spent apart since their last copulation, the more attractive a man rated his partner, independent of the total time since last copulation and independent of the man's relationship satisfaction. Prediction 1 therefore was supported. Total time since last copulation did not independently predict a man's rating of his partner's attractiveness. Relationship satisfaction positively predicted own ratings of partner's attractiveness.

The second row of Table 2 shows that the greater the proportion of time a couple spent apart since their last copulation, the more attractive a man thinks other men find his partner, independent of the total time since last copulation and independent of the man's relationship satisfaction. Prediction 2 therefore was supported. Total time since last copulation did not independently predict a man's rating of other men's perceptions of his partner's attractiveness. Relationship satisfaction positively predicted own ratings of others' assessments of partner's attractiveness.

The third row of Table 2 shows that the greater the proportion of time a couple spent apart since their last copulation, the more interested (or the less disinterested) he is in copulating with his partner, independent of the total time since last copulation and independent of the man's relationship satisfaction. Prediction 3 therefore was supported. Total time since last copulation did not independently predict a man's interest in copulating with his partner. Relationship satisfaction positively predicted copulatory interest in partner.

The fourth row of Table 2 shows that the greater the proportion of time a couple has spent apart since their last copulation, the more sexually interested in him a man thinks his partner is, independent of the total time since last copulation and independent of the man's relationship satisfaction. Prediction 4 therefore was supported. Total time since last copulation did not independently predict a man's assessment of his partner's sexual interest in him. Relationship satisfaction positively predicted assessments of partner's sexual interest in the participant. 
The fifth row of Table 2 shows that that neither the proportion of time a couple has spent apart since their last copulation nor the total time since the couple's last copulation predicted a man's assessment of his partner's sexual interest in other men. Prediction 5 therefore was not supported. Additionally, relationship satisfaction did not predict a man's assessment of his partner's sexual interest in other men.

Finally, the sixth row of Table 2 shows that neither the proportion of time a couple has spent apart since their last copulation nor the total time since the couple's last copulation predicted a man's distress following his partner's denial of his request for copulation. Prediction 6 therefore was not supported. Relationship satisfaction, however, negatively predicted distress following partner's denial of a request for copulation. One of the reviewers of this article suggested that a man who was in a relationship of longer duration might have had experiences in that relationship that would temper distress reactions following a partner's denial of a request for copulation. This reviewer suggested that we might include relationship length as a covariate in our test of Prediction 6. We conducted a second test of Prediction 6, following the analysis presented above. In this second analysis, however, we included relationship length as a covariate. The results did not change, either at the country level or across country. Distress following a partner's denial of a request for copulation was not predicted by the proportion of time apart since last copulation, total time since last copulation, the man's relationship satisfaction, or the length of the couple's relationship (analyses are available from the first author upon request).

\section{Discussion}

This research tested the hypothesis that human male psychology includes mechanisms designed to solve the adaptive problems confronted when a rival might inseminate a partner. Over human evolutionary history, males risked squandering reproductive resources on offspring to whom they were genetically unrelated. A male equipped with psychological mechanisms that motivated him to inseminate his partner as soon as possible following his partner's sexual infidelity would have out-reproduced a male that lacked the requisite mechanisms and therefore took no such "corrective" action. The present research provides empirical evidence that male psychology may include mechanisms designed to solve the adaptive problem of a rival's insemination of a long-term partner.

We assessed the risk of sperm competition as the proportion of time a couple has spent apart since their last copulation. When a couple is apart, a man cannot know for certain his partner's activities. The time a woman spends apart from her partner may be time spent copulating with another man. A woman is increasingly likely to be inseminated by another man with an increasing proportion of time spent apart from her partner since the couple's last copulation (Baker \& Bellis, 1995). We tested six predictions derived from the hypothesis that male psychology includes mechanisms designed to attend to the proportion of time a couple has spent apart since their last copulation as an indicator of the risk of sperm competition. We found support for four of these predictions. A man who spends a greater (relative to a man who spends a lesser) proportion of time apart from his partner since the couple's last 
copulation rates his partner as more attractive, reports that other men find his partner more attractive, reports greater interest in copulating with his partner, and reports that his partner is more interested in copulating with him.

These effects of the proportion of time spent apart since the couple's last copulation are independent of the total number of hours since the couple's last copulation. It is not, therefore, that these men are simply "sexually frustrated" or "sexually pent-up." Total time since the couple's last copulation has no independent predictive effect on any of the dependent variables we examined. A man's motivation to inseminate his partner apparently is not contingent on the time that has passed since he last inseminated his partner, once the proportion of time the couple has spent apart since their last copulation is taken into account. One possibility noted by Daly and Wilson (personal communication, September 2, 2001) for the null effects of total time since last copulation on the target variables is the presence of bidirectional effects between the variables. For a man who copulates with his partner relatively frequently, greater time since last copulation might produce an increase in copulatory interest in his partner, for example. For this same man, an effect opposite in causal direction and in sign also might be operating: Greater interest in copulating with his partner might cause him to initiate copulation with her sooner rather than later, resulting in a shorter duration of time since last copulation. Future research will need to assess a couple's copulatory frequency to investigate the possibility of these opposing effects.

The effects of the proportion of time spent apart since the couple's last copulation also are independent of the man's relationship satisfaction. Regardless of his satisfaction with the relationship, a man who has spent a greater proportion of time apart from his partner since the couple's last copulation appears to be motivated to inseminate his partner sooner than a man who has spent a greater proportion of time together with his partner since the couple's last copulation. Consistent with previous research (see Buss, 1994 for a partial review), a man's relationship satisfaction does independently predict five of the six dependent variables investigated. A man who is more satisfied with the relationship (relative to a man who is less satisfied with the relationship) rates his partner as more attractive, reports that other men find his partner more attractive, is more interested in copulating with his partner, reports that his partner is more interested in copulating with him, and is less distressed by his partner's denial of a request for copulation.

Two of the six predictions tested in this research were not supported. The proportion of time a man spent apart from his partner since the couple's last copulation does not predict his assessment of his partner's sexual interest in other men. The failure of this prediction may have occurred for several reasons. One possibility is that we did not test the prediction we intended to test. Perhaps, for example, we did not validly or reliably measure a man's assessments of his partner's sexual interest in other men. Rather than immediately discarding the failed prediction, it might be worth securing multiple assays of a man's assessments of his partner's sexual interest in other men. Assuming a composite measure that is valid and reliable, we can reexamine the independent predictive influence of proportion of time spent apart since the couple's last copulation on a man's assessments of his partner's sexual interest in other men. One other dependent measure, a man's 
assessments of his partner's sexual attraction to him, was a single-item measure. Although the prediction for this variable was supported, future work also should include multiple-item assessments of this variable.

An intriguing possibility noted by Daly and Wilson (personal communication, September 2, 2001) for the failure of Prediction 5 is that there may be bidirectional effects between the target variables. Prediction 5 stated that a man who spends a greater proportion of time apart from his partner since the couple's last copulation will provide higher ratings of his partner's sexual attraction to other men. Daly and Wilson suggested that an effect opposite in causal direction and in sign also might be operating, with the result that this prediction was not supported. According to Daly and Wilson, a man who provides higher ratings of his partner's sexual interest in other men might, as a consequence, engage in more intense mate guarding, with the result that the couple spends a smaller proportion of time apart since their last copulation. These two effects, opposite in causal direction and opposite in sign, might produce the null relationship identified in this research.

One other prediction failed. The proportion of time a man spent apart from his partner since the couple's last copulation does not predict his distress following his partner's denial of his request for copulation. A possible reason for the failure of this prediction is that we did not test it appropriately. The prediction states that a man who spends a greater (relative to a man who spends a lesser) proportion of time apart from his partner since the couple's last copulation will report greater distress following his partner's denial of a request for copulation, independent of the total time since last copulation and independent of the participant's relationship satisfaction. The test of the prediction, however, asked each man to imagine a scenario in which his partner denied his request for copulation. A better test of this prediction may require that a participant report his distress following his partner's most recent denial of a request for copulation since the couple's last copulation. Distress following a partner's actual denial of a request for copulation then could be regressed on the proportion of time spent apart since the couple's last copulation, total time since the couple's last copulation, and relationship satisfaction. This analysis strategy may have problems, however. The analysis would need to be restricted to men whose partners had denied them copulation in the interim since the last copulation. There might exist factors unknown to the researcher that differentiate a man who does and a man who does not report that his partner has denied him sexual access.

The present research has several important limitations. One limitation of this research is a sample limitation. The mechanisms that may have evolved in response to the adaptive problems of sperm competition are proposed to be universally present in male psychology. The present samples included mostly young men spending time at or around large universities in one of two Western countries. Future work must sample men from different socioeconomic, age, educational, ethnic, and cultural groups.

A second limitation of the present research is a design limitation. We secured one-shot assessments of feelings and desires that were predicted to covary with the proportion of time spent apart since the couple's last copulation. The nature of this design precluded a causal analysis of the relationships between the risk of sperm competition and the psychological reactions to risk of sperm competition. It would be valuable to assess these 
relationships over an extended period of time, such as in a 1-month daily diary study. A daily diary study of couples involved in a committed sexual relationship would allow for a causal analysis of predicted relationships such as the relationship between the proportion of time the couple has spent apart since their last copulation and a man's interest in copulating with his partner.

This research can be extended in several different directions. One such direction, for example, is identifying whether mate retention tactics used by a man in a committed relationship are linked to characteristics of each partner and to characteristics of the relationship (Buss, 1988; Buss \& Shackelford, 1997a; Flinn, 1988). Buss and Shackelford (1997a; see also Buss, 1988) identified 19 different tactics used by people to prevent their spouses from becoming romantically involved with someone else. These tactics varied from vigilance about a partner's whereabouts to violent reprisal for a suspected infidelity. Of particular interest for the present research is whether some of the more devastating male mate retention tactics, such as psychological abuse, physical violence, and sexual coercion, may be linked to the risk of sperm competition. Identifying such links may be a first step to helping women who suffer at the hands of abusive and controlling men (see Daly \& Wilson, 1988; Dobash \& Dobash, 1979; Dutton, 1995; Jacobson \& Gottman, 1998).

In conclusion, this research suggests that human male psychology may include mechanisms designed to solve the adaptive problems of sperm competition. We are not aware of a theory other than Sperm Competition Theory that can account for the predictive utility of the proportion of time spent apart since the couple's last copulation, independent of the total time since last copulation and independent of relationship satisfaction. This research suggests that male humans, like the males of other socially monogamous but not sexually exclusive species, may have psychological mechanisms that are designed to solve the adaptive problem of a partner's sexual infidelity.

\section{Acknowledgments}

The authors thank Dave Bjorklund, David Buss, Bram Buunk, Martin Daly, Todd DeKay, Barry Friedman, Steve Gangestad, Martie Haselton, Erika Hoff, Lee Kirkpatrick, Craig LaMunyon, Rick Michalski, Nick Pound, Percy Rhode, Virgil Sheets, Randy Thornhill, Margo Wilson, and an anonymous reviewer for many helpful suggestions that improved this article.

\section{References}

Baker, R. R., \& Bellis, M. A. (1988). “Kamikaze” sperm in mammals? Animal Behaviour, 36, 937-980.

Baker, R. R., \& Bellis, M. A. (1989a). Number of sperm in human ejaculates varies in accordance with sperm competition theory. Animal Behaviour, 37, 867-869.

Baker, R. R., \& Bellis, M. A. (1989b). Elaboration of the kamikaze sperm hypothesis: a reply to Harcourt. Animal Behaviour, 37, 865-867. 
Baker, R. R., \& Bellis, M. A. (1993a). Human sperm competition: ejaculate adjustment by males and the function of masturbation. Animal Behaviour, 46, 861-885.

Baker, R. R., \& Bellis, M. A. (1993b). Human sperm competition: ejaculate manipulation by females and a function for the female orgasm. Animal Behaviour, 46, 887-909.

Baker, R. R., \& Bellis, M. A. (1995). Human sperm competition. London: Chapman \& Hall.

Bellis, M. A., \& Baker, R. R. (1990). Do females promote sperm competition: data for humans. Animal Behavior, 40, 197-199.

Birkhead, T. R., \& Møller, A. P. (1992). Sperm competition in birds. London: Academic Press.

Burke, T., Davies, N. B., Bruford, M. W., \& Hatchwell, B. J. (1989). Parental care and mating behaviour of polyandrous dunnocks, Prunella modularis, related to paternity by DNA fingerprinting. Nature, 338, $249-251$.

Buss, D. M. (1988). From vigilance to violence: tactics of mate retention among American undergraduates. Ethology and Sociobiology, 9, 291-317.

Buss, D. M. (1989). Conflict between the sexes: strategic interference and the evocation of anger and upset. Journal of Personality and Social Psychology, 56, 735-747.

Buss, D. M. (1994). The evolution of desire. New York: Basic Books.

Buss, D. M., \& Shackelford, T. K. (1997a). From vigilance to violence: mate retention tactics in married couples. Journal of Personality and Social Psychology, 72, 346-361.

Buss, D. M., \& Shackelford, T. K. (1997b). Human aggression in evolutionary psychological perspective. Clinical Psychology Review, 17, 605-619.

Buss, D. M., \& Shackelford, T. K. (1997). Susceptibility to infidelity in the first year of marriage. Journal of Research in Personality, 31, 193-221.

Daly, M., \& Wilson, M. (1988). Homicide. Hawthorne, NY: Aldine de Gruyter.

Dobash, R. E., \& Dobash, R. P. (1979). Violence against wives. New York: Free Press.

Dutton, D. G. (1995). The domestic assault of women. Vancouver: University of British Columbia Press (rev. ed.).

Flinn, M. V. (1988). Mate guarding in a Caribbean village. Ethology and Sociobiology, 9, 1-28.

Gage, M. J. G. (1997). Continuous variation in reproductive strategy as an adaptive response to population density in a moth, Plodia interpunctella. In: Proceedings of the royal society of London: B, vol. 261 (pp. 25-30).

Gangestad, S. W., \& Thornhill, R. (1997). The evolutionary psychology of extrapair sex: the role of fluctuating asymmetry. Evolution and Human Behavior, 18, 69-88.

Gangestad, S. W., \& Thornhill, R. (1998, July). The scent of symmetry: evidence for a human sex pheromone. Paper presented at 10th Annual Human Behavior and Evolution Society Conference, Davis, CA.

Jacobson, N., \& Gottman, J. (1998). When men batter women. New York: Simon \& Schuster.

Parker, G. A. (1970a). Sperm competition and its evolutionary consequences in the insects. Biological Review, 45, $525-567$.

Parker, G. A. (1970b). The reproductive behaviour and the nature of sexual selection in Scatophaga stercoraria: V. The female's behaviour at the oviposition site. Behaviour, 37, 140-168.

Parker, G. A. (1984). Sperm competition and the evolution of animal mating strategies. In: R. L. Smith (Ed.), Sperm competition and the evolution of animal mating systems (pp. 1-60). London: Academic Press.

Pound, N. (1998, July). Polyandry in contemporary pornography. Paper presented at 10th Annual Human Behavior and Evolution Society Conference, Davis, CA.

Shackelford, T. K., \& Buss, D. M. (1997a). Anticipation of marital dissolution as a consequence of spousal infidelity. Journal of Social and Personal Relationships, 14, 793-808.

Shackelford, T. K., \& Buss, D. M. (1997b). Spousal esteem. Journal of Family Psychology, 11, 478-488.

Shackelford, T. K., \& Buss, D. M. (2000). Marital satisfaction and spousal cost-infliction. Personality and Individual Differences, 28, 917-928.

Singh, D., Meyer, W., Zambarano, R. J., \& Hulbert, D. F. (1998). Frequency and timing of coital orgasm in women desirous of becoming pregnant. Archives of Sexual Behavior, 27, 15-29.

Smith, R. L. (Ed.). (1984a). Sperm competition and the evolution of animal mating systems. New York: Academic Press. 
Smith, R. L. (1984b). Human sperm competition. In: R.L. Smith (Ed.), Sperm competition and the evolution of animal mating systems (pp. 601-660). New York: Academic Press.

Tabachnick, B.G., \& Fidell, L.S. (2001). Using multivariate statistics. (4th ed.). Boston: Allyn \& Bacon.

Thornhill, R., \& Alcock, J. (1983). Evolution of insect mating systems. Cambridge, MA: Harvard Univ. Press.

Thornhill, R., Gangestad, S. W., \& Comer, R. (1995). Human female orgasm and mate fluctuating asymmetry. Animal Behaviour, 50, 1601-1615.

Trivers, R. L. (1972). Parental investment and sexual selection. In: B. Campbell (Ed.), Sexual selection and the descent of man (pp. 139-179). London: Aldine. 